\title{
Las fronteras entre poder, Estado y medios de comunicación masiva desde la teoría crítica
}

\author{
Manuel Ortiz Marín*
}

Resumen. Se presenta una concepción de poder, desde la mirada de la Teoría Crítica, que permite comprender el complejo tejido que engarzan las relaciones de poder a la mayoría de las actividades humanas. Asimismo se aborda el papel del Estado como elemento regulador de las distintas fuerzas de carácter institucional que operan en su interior como estructuras de poder y la función que cumplen los medios de comunicación masiva en la complejidad de las sociedades modernas.

Palabras clave: poder, Estado, medios de comunicación masiva, sistema social, sistema de comunicación.

\begin{abstract}
A conception of the power, from the glance of the Critical Theory that it allows to understand the woven complex that links the relations of power to most of the human activities. This paper also approaches to the State as a regulating element of the different forces from institutional character, that they operate in its interior like structures of power and the function as that the massive mass media in the complexity of the modern societies act.

Keywords: power, State, massive media, social system, communication system.
\end{abstract}

* Académico de la Facultad de Ciencias Humanas de la Universidad Autónoma de Baja California. Correo electrónico: mortiz@uabc.mx 
En este ensayo se presenta una concepción de poder, desde la mirada de la Teoría Crítica, que permite comprender el complejo tejido que engarzan las relaciones de poder a la mayoría de las actividades humanas. Asimismo se aborda el papel que tiene el Estado como elemento regulador de las distintas fuerzas de carácter institucional (gobierno, policía, fuerza armada, partidos políticos y escuela) que operan en su interior como estructuras de poder y la función que cumplen los medios de comunicación masiva en la complejidad de las sociedades modernas. En el interés de ampliar la noción de Estado, se contrasta el enfoque crítico con las teorías normalistas-juristas que le otorgan al mismo la función de armonizar a la sociedad. La finalidad central del ensayo es provocar la reflexión acerca de cómo en las relaciones humanas más significativas, así como en las cotidianas, el poder posee esta cualidad envolvente que permite al individuo, así como a la sociedad en la que se halla inmerso, construir relaciones de poder con el Estado y los demás aparatos ideológicos que las sociedades modernas han producido, pero también al interior de la interrelación humana. De manera especial, se aborda el comportamiento de los medios de comunicación masiva, ya que éstos constituyen hoy en día un elemento sustancial y articulador del tejido social, y forman parte del entramado que permite al poder expresarse y legitimarse.

\section{Poder como constructo social}

¿Qué es el poder? ¿Cómo apropiarse de él? ¿Cómo entender sus manifestaciones al interior y exterior de las redes sociales? Preguntas como éstas son permanentes entre quienes ejercen el poder y aquellos que aspiran a oponérseles para, posteriormente, detentarlo. Interrogantes que guiarán este apartado, con la única finalidad de establecer un común denominador que permita la explicación y comprensión de dicho acto humano, a efecto de lograr su operacionalización en un proceso de desarrollo teórico.

Pero antes de continuar conviene, para los propósitos del texto, expresar qué no es el poder desde la perspectiva de la Teoría Crítica que se utiliza para el análisis. El poder no reside o puede residir en una sola persona o cosa. No son instituciones como el Estado, concepción muy 
propia de enfoques liberales, como de algunos marxistas que lo asumen dentro de una visión instrumental; el poder no le pertenece sólo al gobernante, sea cual sea su ideología. Ni reside únicamente en instituciones como el gobierno, por más que las explicaciones liberales lo justifiquen en función de servir al bien común tanto de los individuos como de la sociedad. Desde la noción del neocapitalismo, son las empresas y los consorcios transnacionales los todopoderosos que detentan el poder sobre los individuos y las naciones.

Tampoco el poder reside únicamente en las cosas materiales, como los bienes de capital (aunque en mucho se le representan), ni en las armas, ni en la fuerza física ni en la psicológica como formas de control y dominación sobre los individuos. En conjunto, estas perspectivas conducen a mostrar al poder como algo cosificado, que prevalece en un objeto y que una vez identificado se puede delimitar en una instancia específica e incluso medir, como propone Deutsch (1971). Considerar al poder de forma estática es un error de apreciación. Creer que sólo reside en un individuo, grupo o clase es una idea equivocada o una visión reduccionista del mismo.

Entonces, ¿qué es el poder? O mejor dicho, ¿qué cosa es el poder? La primera premisa es que el poder y la función que tiene al interior de cualquier sociedad representan un fenómeno social. El poder maniobra a través de una organización reticular; una definición más nominal la ofrece Foucault: "El poder transita transversalmente, no está quieto en los individuos" (1991: 144). No es un atributo como la riqueza. El poder circula, funciona en cadena. Circula a través del individuo, no contra él. Éste es un efecto y una conexión del poder.

Apuntaríamos como una inicial definición que el poder se concibe como un constructo social y es el resultado de la interacción cotidiana de los individuos, de ese tejido invisible que desde la intersubjetividad se hila entre los sujetos, lenta o violentamente, según el caso. Como tal reside en cada uno de los elementos constitutivos de lo que hoy se denomina sociedad moderna. En el sentido social, se convierte de generar capacidad de obrar, en capacidad del hombre para determinar la conducta del hombre. Es decir, el individuo no es sólo sujeto del poder sino también el objeto de éste. 
El poder es una relación social entre hombres, específicamente es aquel que un hombre (o grupo) tiene o ejerce sobre otro hombre (o grupo). Si bien se ha comprendido que el poder no se halla depositado en un solo ente como pudiera ser el Estado, sí se le reconoce a éste su carácter institucionalizador y regulador. En oposición a la Teoría Crítica, la perspectiva normalista-jurista asume la relación entre poder y Estado como la capacidad para proponer y construir los consensos adecuados, además de crear y formular los espacios necesarios y suficientes para la actuación de las instituciones reguladoras y los agentes sociales. El poder sólo puede operar mediante -y sólo dentro de- la normalidad o las leyes establecidas por el Estado.

De esta forma, los aparatos del Estado (sistema escolar, gobierno, partidos políticos, ejército, Iglesia, industrias culturales y medios de comunicación masiva) son expresiones o ámbitos de construcción e interacción de las relaciones de poder. Pero también de la elaboración del tejido social, que a su vez reconstituye las relaciones de poder de estos aparatos.

Desde la perspectiva crítica, Acanda plantea este pensamiento de una forma muy lúcida al decir que "el estatuto ontológico del poder no es el de un ente objeto, sino el de un complejo sistema de relaciones. El poder es relación de fuerzas. Por lo tanto, no surge después de que se ha estructurado el todo social, sino que es elemento de su conformación" (2003: 115). Luego entonces, se puede afirmar que el poder es un fenómeno social, y sociedad y poder interactúan y se reproducen a sí mismos, como parte de expresiones de poder.

Asimismo, hay un ente denominado Estado, que se expresa como institución en la figura llamada gobierno, entidad creada por el hombre y legitimada por la sociedad, que intenta regular las relaciones de poder $\mathrm{y}$, a su vez, es expresión de esas relaciones de poder. Los binomios individuo-sociedad, por una parte, y Estado-gobierno, por otra, son ejes vertebradores de un escenario social en el cual se reproducen las relaciones de poder y conllevan a la especificidad de sus cualidades intrínsecas. Pero al mismo tiempo, en su interior se expresan múltiples formas de tensión entre la búsqueda del consenso para la armonización de lo social y el conflicto permanente en que se desenvuelve el individuo que intenta subvertir el control y la 
violencia generados por los instrumentos normativos del Estado vigilante.

El abordaje del binomio individuo-sociedad se puede plantear desde la tesis gramsciana para formar parte de la denominada sociedad civil, la cual, junto con la sociedad política, se concibe como un Estado "ampliado", es decir, un espacio en el cual tienen lugar relaciones de poder, debido a la naturaleza propia de organizaciones de tipo político, las estructuras como las de carácter jurídico y toda forma de relaciones sociales e históricas que la integran y actúan como responsables de la elaboración y difusión de las ideologías (Gramsci, 1998).

La conceptualización de la hegemonía de la sociedad civil proviene de la comprensión de la importancia de mecanismos de producción de hábitos de comportamiento, valores y modos de pensar en la estructuración del poder por los individuos en las sociedades modernas. En contraste se localiza a la sociedad política, la cual según Gramsci se identifica claramente con la noción de Estado y es definida por Coutinho como

el aparato de coerción estatal que asegura legalmente la disciplina de aquellos grupos que no consienten ni activa ni pasivamente, pero que está constituido considerando toda sociedad, en previsión de los momentos de crisis de comando y dirección "en los aparatos privados de hegemonía", casos en que el consenso espontáneo desaparece (2000: 26).

Acanda plantea dos distinciones para comprender la interrelación entre sociedad civil y sociedad política como parte de la teoría de la hegemonía:

En primer lugar, la distinción entre sociedad política y sociedad civil no es orgánica, sino tan sólo metódica. Un partido político forma parte de una sociedad política, pero si logra insertarse en el proceso de producción y/o distribución de normas de valoración y comportamiento, se inscribirá a la vez en la sociedad civil. La relación entre ambas sociedades se concibe bajo la idea de "unidad-distinción" (2002: 255). 
Una posición imprescindible para la actuación del individuo ante un acto de poder, es la voluntad para ejercer éste o ser dominado por quien lo posee. Como afirma Foucault: "las masas desean que se ejerza el poder, aún conscientes de que este poder se ejercerá sobre ellas y a sus expensas [...] desean que ese poder sea ejercido" (1984: 17). Es decir, que para que el poder se manifieste y opere sobre los individuos requiere de la voluntad de ellos mismos. El poder se logra cuando hay alguna intención determinada o decisión o secuencia de decisiones por las cuales su aplicación pueda guiarse y dirigirse. De tal manera que para un individuo el acto de ejercer el poder, o el de ser objeto de él, es un acto de voluntad que requiere de la aceptación o rechazo de la acción del poder.

En el ánimo de participar de visiones contrastantes a la Teoría Crítica, se aborda la noción normalista-jurista del papel del Estado. La comprensión del concepto de Estado moderno lleva por naturaleza a buscar sus orígenes en las primeras agrupaciones de carácter simple que el hombre formó. Algunos estudiosos del tema pensaban que "el Estado había surgido de la asociación, es decir, de una agrupación de personas que, dentro de una sociedad, se unen con fines específicos y que al margen de los vínculos de la comunidad local y de los lazos de parentesco, hacen que las personas se unan dentro de una agrupación social" (Krader, 1972: 12).

Al respecto, sociólogos y antropólogos modernos rehúsan reconocer como Estado a las sociedades caracterizadas por etapas incipientes de desarrollo y sobre todo basadas en una estructura tribal. Habrá que reconocer que el progreso de la sociedad lleva aparejada la construcción del Estado, a pesar de que en el siglo XIX se consideraba que podía haber sociedad sin Estado (Akzin, 1964).

Desde la visión normalista, el Estado ocupa un lugar central en la explicación del desarrollo de la sociedad, para ello se apoya en fuerzas integradoras como la lealtad, la dependencia recíproca, la tradición, la fe religiosa y la fuerza de la costumbre. Elementos que articulados permiten la interacción entre el hombre y un aparato que administra, castiga y premia la actuación de aquél dentro de la sociedad. Córdova (1976) refiere al Estado como un conjunto de instituciones sociales a partir de las cuales se garantiza la 
organización de la sociedad para el desarrollo de sus actividades en todos los órdenes de la vida.

En este orden de ideas, una función que ejerce el Estado, íntimamente vinculada a la acción anterior, está constituida por la naturaleza legitimadora de la acción ideológica, entendida como el proceso y el resultado de la identificación de un orden sociopolítico afirmado como ideal de la comunidad y del Estado, ${ }^{1}$ y que uno de sus elementos, el gobierno, rige a la primera y encarna al segundo (Kaplan, 1978). Para actuar dentro del contexto específico de una legitimación, el Estado requiere atribuirse la voluntad de la sociedad que mediante su consenso confirme la actuación de aquél.

Esta voluntad del individuo para ejercer el poder o aceptar su ejercicio conlleva un acto esencial en las relaciones sociales: el consenso, entendido como el consentimiento en las decisiones colectivas aceptadas como propias, lo que conduce al individuo a solidarizarse y participar del ejercicio del poder como un todo. Pero el poder también aspira al reconocimiento por parte de los dominados, y en las sociedades democráticas la legitimidad se busca y obtiene mediante el consenso. Es así como la búsqueda y obtención del consenso viene a ser otra de las funciones del Estado y representa el acuerdo general de los grupos o la voluntad de los individuos constituyentes de una sociedad sobre la legitimidad de una forma de Estado y de un gobierno determinado.

En oposición a esta perspectiva, los enfoques críticos entienden al Estado en términos del ejercicio instrumental del poder por las personas ubicadas en posiciones estratégicas, sea de forma directa por medio del manejo de las políticas del Estado, o indirectamente mediante la presión sobre el mismo (Sonntag y Valecillos, 1977). Gramsci, uno de los más importantes estudiosos contemporáneos del Estado desde la corriente marxista, se expresa de él como

un organismo propio de un grupo destinado a crear las condiciones favorables para la máxima expansión del mismo

${ }^{1}$ Lo anterior se refiere a la clásica teoría de los elementos del Estado (poder público, territorio y población), que configura "un modo de encarar la validez del orden jurídico, ya sea en sí misma, ya en su alcance territorial o personal" (Kelsen, 1968: 195). 
grupo; pero este desarrollo y expansión son concebidos y presentados como la fuerza motriz de una expansión universal, de un desarrollo de todas las energías nacionales. El grupo dominante es coordinado concretamente con los intereses de los grupos subordinados y la vida estatal es concebida como una formación y superación continua de equilibrios inestables (1998: 72).

Ahora bien, es preciso determinar el corpus del Estado desde la Teoría Crítica, sin dejar de reconocer las tesis liberales. El paradigma crítico muestra al Estado como un ente regulador de las distintas fuerzas que operan en su interior, ya que condensa costumbres sociales muy diferentes y las transforma adecuándolas para funcionamiento de la normalización y, por ende, de la dominación sobre clases determinadas y otros grupos sociales. Estas costumbres se amalgaman para ser una costumbre sistemática de regulación, de pauta y de normalización, dentro de la sociedad. Es decir, en el Estado cohabitan diferentes expresiones de las costumbres sociales, producto de las relaciones socioeconómicas de la sociedad. Pero se requiere que se transformen en una sola costumbre para ser normada y de hecho controlada por el Estado (Hall, 1998).

Para ello, el Estado opera mediante dos vertientes: el poder del saber y el poder legal. Para el primero, lejos de la concepción tradicional del poder como prohibición o negación, Foucault (1991b) propone asumir al poder como esa fuerza que produce cosas, induce al placer, forma saber y produce discursos. Habrá que entenderla como una red productiva que atraviesa todo el entramado social, en lugar de una instancia que sólo funciona para reprimir. Luego entonces el escenario será en donde quien tiene el saber, posee el poder.

Este último se verá multiplicado por el saber y viceversa. El poder seguirá en manos de especialistas del poder, de quienes son expertos en el ejercicio del poder y para quienes el poseerlo es la razón primaria de su existencia. De tal forma que habrá una nueva economía del poder, mediante procedimientos que hacen circular los efectos del poder del saber de forma adaptada al corpus social, y una de las 
herramientas más perfeccionadas son los medios de comunicación masiva (МСм), con toda su carga ideológica y tecnológica, como explicaremos más adelante.

El poder legal se ejerce mediante el derecho como una herramienta normativa y reguladora de la actuación del individuo al interactuar al interior del espectro social. Para ello, el derecho asume dos posiciones: la primera, desde la funcionalidad de las leyes, para procurar la soberanía y la obediencia a éstas. "El hecho de poseer los instrumentos del poder no basta, es necesario haberlos adquirido observando ciertas reglas y principios que confieren el derecho, universalmente reconocido de gobernar" (Bobbio y Bovero, 1985: 21); este reconocimiento de la legitimidad legal transforma una relación de fuerza en una relación de derecho.

De ahí que el derecho procura la dominación y el sometimiento de los individuos al poder soberano legitimado mediante las leyes. La imposición del poder normalizado o legal se superpone en esta mirada diaria, según las condiciones históricas, al poder brutal. De tal forma que es la cotidianidad, producto de la vida social, el objeto de la regulación del poder legal. Este quehacer diario, en los tiempos actuales, es ampliamente sustentado por los MCM, mediante los cuales transita el devenir social.

Cuando el poder reduce las capacidades de elección y el individuo transgrede las leyes, una de las formas de actuación del poder legal es la coerción, entendida como "la renuncia a las ventajas de la 'selectividad' del compañero. La persona que ejerce la coerción debe asumir la carga de la selección y la decisión en el mismo grado en que se ejerce la coerción; ésta tiene que ejercerse donde hay una carencia de poder" (Luhmann, 2000: 14). El caso extremo es cuando se usa la fuerza física para sustitución de la acción de otros por la acción propia. Esta coerción no es propia de los sistemas simples, sino más bien de los sistemas complejos, y éstos requieren desarrollar poder para hacer posible la coerción. Éste sería el límite del poder, que al perder su carácter simbólico, se convierte en un instrumento que asegura la obediencia de los deseos en lugar de las obligaciones y para ello hace uso de la coerción e incluso de la violencia física. 


\section{Funcionalidad política del poder}

Luego entonces, habrá que entender el poder como un entramado complejo e identificado en lo profundo de las relaciones sociales. Penetra en todas las raíces de las relaciones sociales y éstas manifiestan diferenciales de poder según la complejidad de la sociedad. Uno de los escenarios de su comprensión sería mediante su funcionalidad política y económica. El poder mantiene dos ejes centrales de su actuación social mediante el poder político, caracterizado por el aparato más clásico que es el Estado; éste a su vez ha configurado como instrumento a los partidos políticos, concebidos como formas refinadas y legitimadas de participación de la sociedad política.

También se asume mediante el poder económico, caracterizado en las economías capitalistas por la empresa burguesa. El poder económico procede de la actividad humana productiva, es decir, "de la actividad que se ocupa de abastecer de los medios de subsistencia a través de la extracción de las materias primas y su transformación en bienes que pueden consumirse o intercambiarse en el mercado" (Thompson, 1998: 31).

Le dedicaremos más atención al poder político por la naturaleza misma del sentido de este ensayo. Éste proviene de la actividad de coordinar a los individuos y regular sus formas de interacción. Cualquier forma $u$ organización que se favorezca de este proceso conlleva implícita una forma de poder político. Weber (1984) plantea una simbiosis entre poder y política. Para el filósofo alemán, quien hace política aspira al poder, entendido como el medio de consecución de otros fines, o al poder para gozar del sentimiento de prestigio que él confiere. Dicha interacción se ejerce por la vía de instituciones que operan en un espacio específico y de forma centralizada.

Una de las instituciones más representativas y legitimadas, como se ha visto anteriormente, es el Estado. Éste constituye una forma de autoridad, otorgada consensuadamente por los ciudadanos en la mayoría de las ocasiones. La autoridad, para la tarea política, recurre a dos manifestaciones distintas pero relacionadas: el poder coercitivo y el poder simbólico. La primera utiliza o puede usar la fuerza física, y la segunda defiende la autoridad del Estado mediante la difusión 
de formas simbólicas que cultivan una legitimidad del poder político. Su función es la de unir o articular toda una gama de discursos políticos y costumbres sociales, que se relacionan con la transmisión y la transformación del poder. Algunas costumbres tienen que ver con el campo político, pero otras relacionan al Estado con la sociedad civil.

En el interés de ampliar el conocimiento y la comprensión del Estado, a partir de visiones diferentes e incluso que ofrezcan matices contrastantes, resulta pertinente precisar las funciones que desarrolla mediante su estructura orgánica y los estadios de actuación del mismo. Es decir, la conformación que el Estado asume para actuar en relación con la sociedad y los ámbitos de carácter ideológico, económico y jurídico en que participa de forma normalizadora, según las tesis ya citadas. A fin de comprender y explicar mejor este postulado, habrá que considerar que autores como Heller (1985) conciben al Estado como una unidad que opera en la realidad histórico-social, como una estructura real e histórica. Por ende, las funciones del Estado actúan en permanente evolución.

Una de las funciones atribuidas al Estado es su carácter institucionalizador de las relaciones grupales o individuales, y que a su vez se constituyen en un orden institucional en los planos económico, político, militar, familiar y religioso (Kaplan, 1978). Este conjunto de instituciones se encarga de normar la adquisición, el ejercicio y la distribución del poder; el monopolio y la organización de la violencia legítima dentro del orden político-militar; la organización de los recursos para la producción de bienes y servicios en el ámbito político; y la definición de las características de la formación de la familia, en términos de conductas sexuales y mecanismos de procreación, y en la determinación de normas que atañen al culto religioso. Esta capacidad institucionalizadora no se adquiere ni se mantiene de forma natural, demanda del Estado actuar con un carácter legitimador y consensual a efecto de buscar la preservación de las instituciones.

Para el Estado, los partidos políticos son los instrumentos apropiados para legitimar la política como procurador del consenso permanente. Una concepción de política que la vincula al poder como imposición, y que se complementa con otra, que la vincula al consenso. Las instituciones políticas, por la naturaleza propia de su 
quehacer, generan normas y regulaciones, y una de ellas es regular el papel político de los medios. Éstos son vitales para la legitimación de la autoridad política y cumplen funciones de articulación política, movilidad y control de conflictos.

Las interrelaciones de instituciones como los partidos políticos, con un fuerte componente político y reconocido como tal, y los MCM están condicionadas por las relaciones mutuas de poder, ambas nacen de sus relaciones respectivas con la sociedad. El poder de las instituciones políticas es inherente a "sus funciones articuladoras de intereses y movilizadores de poder social para fines de acción política" (Gurevitch y Blumler, 1981: 312). Es en este proceso en el cual la actividad política ha transformado su ejercicio, pasando de la tribuna y el auditorio a la intermediación de lo mass-mediático.

Para comprender mejor este escenario de la política actual, tendremos que estar de acuerdo en que ésta ha trasladado, en la modernidad que nos envuelve, su quehacer, lenguaje y práctica del racionalismo elaborado y academicista, al desorden, banalidad e incluso a la vulgaridad de lo mass-mediático.

Una de las consideraciones importantes para entender la lógica de los medios en una economía globalizada es que éstos se interesan por atraer a audiencias de alto poder adquisitivo, y no audiencias per se. Por tal razón, Chomski y Herman (1990) afirman que un movimiento de masas, como puede ser un partido político, que no cuente con el apoyo de los MCм más importantes, y esté sometido al ataque de medios influyentes, está en desventaja ante las críticas de sus enemigos y contendientes contrarios. De tal manera que el poder político ahora se juega y distribuye no en la arena del discurso, sino en la retórica hueca de los presentadores de noticias y debates electorales. Como lo indica Bisbal, "la cultura política ya no está ante el sujeto homogéneo de los partidos tradicionales sino ante uno múltiple, cuya compleja vida diaria no puede ser expresada por un solo tipo de discurso" (2004: 27).

\section{El poder y la mediación social de los MCM}

Una de las acepciones más comunes y propuesta por varias teorías del poder (cfr. Gramsci, 1998; Foucault, 1984; Bobbio, 1985; y Acanda, 
2002, entre otros) es su asociación con el acto de represión o prohibición. Y es el Estado a quien suele personificársele con este papel. La naturaleza prohibitiva pareciera ser una característica natural de quien posee el poder, sea una institución (como el Estado), un grupo (empresa, familia), un individuo (líder) o una organización (partido político). La posesión del poder otorga la capacidad de obligar, ya sea por la fuerza física (coerción) o psicológica (coacción), a ejecutar actos en contra de la voluntad de otros, e implica la posesión de aparatos de control de la voluntad y vigilancia de los actos de quienes no tienen el poder.

En estos tiempos que se debaten entre la modernidad y la posmodernidad, conforme más compleja y amplia sea la red de poder, los instrumentos de control serán a su vez más sutiles para ejercer acciones como la producción de sentido, la formación de valores, la generación de necesidades o comportamientos de consumo, importantes dentro de una sociedad globalizadora, además de actitudes de vigilancia de los individuos a los cuales se quiere someter. Dichos aparatos existen desde la antigüedad, como son las estructuras religiosas, la organización familiar, las fuerzas armadas y el sistema escolar; sin embargo, sus procedimientos y mecanismos se han perfeccionado y abarcan a más sectores de la sociedad y son cada vez más legitimados por el aparato judicial.

Hay otros aparatos a los que el avance científico-tecnológico les ha investido de mayores capacidades de control e incluso compiten con los anteriores. Son las industrias culturales cuya eficacia, cobertura y capacidad mediática les dotan de mayor legitimidad y uso por la mayoría de los sectores de la sociedad moderna, y su ejemplo más acabado son los $\mathrm{MCM}^{2}$ como comúnmente son conocidos. ${ }^{3}$ Es pertinente

\footnotetext{
${ }^{2}$ Thompson (1998) expresa la comunicación como la actividad social que implica la producción, transmisión y recepción de formas simbólicas, que emplea medios técnicos que a su vez poseen ciertos atributos como: fijación o preservación, capacidad de reproducción y grados de separación espacio-temporal (contextodescontextualización).

${ }^{3}$ Se hará referencia al término MCM cuando se trate de aquellos dispositivos técnicos que tienen por denominación común a la prensa, la radio, la televisión y el cine.
} 
aclarar la referencialidad de lo masivo. En este sentido, una de las características más destacadas de la comunicación de masas proviene no del número de individuos que reciben los productos, sino del hecho de que los productos están disponibles a una pluralidad de destinatarios. En ello deviene la discusión acerca del concepto de masa que sugiere individuos pasivos desde una perspectiva ya rebasada de la crítica a la cultura de masas. Esta concepción ha sido abandonada, ya que el proceso de recepción es muy complejo y más aún cuando los contenidos simbólicos son apropiados e incorporados a la cotidianidad de los individuos.

Por tal razón, se le reconocen a los MCM tres rasgos de poder: simbólico, estructural y normativo. Para el primero de ellos, la recepción de los productos implica una actividad en la cual los individuos reelaboran los materiales que reciben. Es así como se construye el poder simbólico desde "la realidad que aspira a establecer un orden gnoseológico; el sentido inmediato del mundo (social)" (Bourdieu, 2000: 91).

Por lo tanto, la recepción es una "actividad situacional" ya que los individuos están ubicados en contextos sociohistóricos específicos y depende de ellos, del poder, de los recursos disponibles y de la capacidad de recepción. La recepción también es "rutinaria", ya que constituye una parte integral de las actividades de la vida cotidiana. Además es un "logro habilidoso" ya que depende de la variedad de habilidades y competencias que los individuos despliegan para llevar a cabo la recepción.

El poder aspira a representar la concepción simbólica de la realidad. De tal forma que los procesos de comunicación están en todo momento imbuidos de poder (Flyvbjerg, 2001). Por lo tanto, las relaciones de comunicación son relaciones de poder dependientes, en su forma y contenido, del poder material o simbólico, representado este último por los agentes o instituciones implicadas en la acumulación de este tipo de poder. Los sistemas de esta naturaleza más representativos son los мсм, los cuales actúan como legitimadores de la dominación y contribuyen a asegurar la hegemonía de una clase sobre otra, llamada por Weber, citado por Bourdieu, "la domesticación de los dominados" (2000: 94). La lucha por la dominación proviene de la 
cultura dominante y se manifiesta en la cotidianidad mediática, por imponer una visión simbólica de la realidad social conforme a sus intereses particulares.

En este proceso desempeñan un papel importante los productores de sentido (intelectuales orgánicos), cuya tarea es procurar inculcar instrumentos de conocimiento y de expresiones arbitrarias (ajenas y extrañas) a la realidad social. En este campo de producción que se vehicula mediante los MCM, se representa una lucha simbólica al interior de la clase dominante. Estos grupos que sirven a sus propios intereses y cuyo poder reposa fundamentalmente en el capital económico tienden a imponer la legitimidad de su dominación por dos mecanismos: en primer lugar, mediante la producción simbólica, como serían los bienes y el dinero; y en un segundo, por los ideólogos conservadores que sirven a los intereses de la clase dominante.

A su vez, el poder estructural se refiere a las características que asumen los MCM al poner ciertos mensajes al alcance de un público que, por su composición, no tiene acceso a otros medios, y la cualidad estructurante principal es el componente tecnológico de los medios. No se debe ocultar que el desarrollo mediático es primordial para la reelaboración del carácter simbólico de la vida social cotidiana. El contenido y la información simbólica se producen e intercambian en la esfera social y a su vez reestructuran las interrelaciones de los individuos entre sí.

Geertz, dice Thompson, lo explicó de la siguiente manera: "los MCM constituyen las ruecas del mundo moderno y, al utilizar estos media, los seres humanos se convierten en fabricantes de tramas de significado para el consumo propio" (2000: 26). De tal manera que la comunicación mediática siempre es un fenómeno social contextualizado: forma parte de contextos sociales estructurados de varias formas y a su vez tienen un impacto estructural en los actos comunicativos. En y desde la cotidianidad se reproduce el poder normativo. La cotidianidad, producto de la vida social, se sustenta en los MCM, mediante los cuales transita el acontecer diario.

En esta mirada permanente, la imposición del poder normalizado se superpone, según las condiciones históricas, al poder brutal. De tal manera que el poder se produce y reproduce en el tejido de la 
vida cotidiana, y se encuentra en cualquier producto o relación social de los sujetos. La raíz normativa del poder de los medios es crucial en épocas de controversia, y se funda en el reconocimiento al papel que pueden tener en el campo político, merced a su credibilidad e independencia. Sin embargo, habrá que reconocer las limitantes de los mismos, dadas las condicionantes estructurales de poder en que operan los propios мСм.

Los massmedia ampliaron la esfera de lo público y expusieron el quehacer político a la mirada múltiple de las audiencias, con ello transformaron la concepción tradicional del vocablo poder, para convertirlo en el poder mediático. En esencia, la tarea de los medios es clara: evitar la comprensión del fenómeno social y dirigir la mirada de sus audiencias a temas o hechos convenientemente estructurados a los intereses de los grupos en el poder empresarial o político. Para tal tarea, los MCM requieren dirigirse y servir a la opinión de las élites, ofrecer un perfil óptimo para los anunciantes y desempeñar un papel adecuado en la toma de decisiones en la esfera pública y privada (Chomsky, 1990).

Para entender qué ocurre en la construcción del cambio social mediante el uso de la información, y su impacto en la conciencia de los sujetos (imaginario colectivo), se necesita aclarar qué aportan los productos comunicativos para que se acepten como propias las interpretaciones del mundo que regularmente son contrarias tanto a la objetividad como a los intereses de la mayoría de los receptores. Martín Serrano afirma que "la representación ideológica de la realidad ofrece un modelo de mundo reconocible en el entorno o fácticamente posible; sugiere a los actores comportamientos factibles y aceptables, y describe situaciones que suelen ser las más probables" (1989: 23).

Esta condición ideológica da por supuesto que ese funcionamiento social es el único que merece ser conservado, legitimado y viable. Dicha percepción implica que se desconozca el pasado y se acepten sólo los hechos inmediatos. Sin embargo, la transformación de la realidad no es inmediata, ni se puede esperar que únicamente y gracias a los MCM esto se logre. Si bien se puede acelerar, también habrá que reconocer que dicho proceso depende de factores del entorno. 
Desde una perspectiva opuesta, proveniente de las tesis funcionalistas, particularmente la derivada de los enfoques norteamericanos de teóricos como Berelson, Schramm y Laswell, entre otros, acerca del poder de los MCM, se asume que la comunicación tiene por finalidad reproducir representaciones colectivas estables y confiables. El sujeto adquiere por medio de los MCM un conjunto de datos de referencia, provenientes de una experiencia elaborada socialmente, previa a la recepción de la información, para así constituir experiencias subjetivas que conforman su sistema cognitivo.

Es decir, las narraciones del acontecer público ${ }^{4}$ que emiten los medios están interesadas en lo que permanece, más que en lo que cambia de la realidad. Martín Serrano indica que

la característica de la información que se obtiene mediante los MCM, radica en que ha sido seleccionada y preelaborada por la tarea expresiva de otro $\mathrm{u}$ otros actores diferentes del usuario. Por esa razón, la consonancia entre el acontecer y el conocer que quepa atribuir al efecto de la comunicación, está mediada por el Alter; y cuando el mediador actúa a través de los MCM, que son instituciones sociales, la mediación está institucionalizada (1989: 43).

Es pertinente hacer un paréntesis para ampliar estos conceptos, ya que de suyos son importantes para la comprensión de los procesos mediáticos. Para Martín Barbero el concepto de mediación se explica desde un pensamiento histórico como "la relación de la transformación en las condiciones de producción con los cambios en el espacio de la cultura, es decir las transformaciones de los modos de percepción, de la experiencia social" (1987: 86).

En el proceso de apropiación de la información, también la condición cultural aporta sus elementos al influir en las predilecciones

${ }^{4}$ Se entiende por acontecer público: "cualquier emergente (cosa, objeto, suceso, observación, idea, norma, relación, etc.) que por su presencia o ausencia afecta o puede afectar a la comunidad y cuyo conocimiento puede ser compartido por los miembros de aquella, porque ha sido seleccionado como objeto de referencia por las instituciones que tienen a su cargo dar noticia pública de lo que acontece" (Martín Serrano, 1989: 53). 
conformando la cultura del receptor, mediada por el entorno social en que está inmerso y la influencia gradual o parcial de las interacciones individuales o grupales (Orozco, 1991). Las identidades sociales del sujeto-receptor (S-R) forman parte de las mediaciones referenciales que afectan la recepción de productos mediáticos. La inscripción del $\mathrm{S}-\mathrm{R}$ al interior de las instituciones sociales implica la recepción, intercambio, producción e interacción de significados comunicativos. Es necesario reconocer que cada institución social, como la escuela, la familia, los grupos de adscripción social o los partidos políticos, tiene su expresividad y espacio propio que se significa por los sentidos y símbolos que producen y difunden, de ahí la utilidad e importancia mediática de los MCM.

Landi (1992) sugiere que el actuar de los medios en tiempos de crisis, a diferencia de los partidos, es reaccionar rápidamente a las expectativas de la sociedad en cuanto a información, adelantándose así a los actores sociales. En los procesos de diferenciación social, los partidos políticos desmerecen ante los MCM, ya que éstos cubren las brechas entre el ciudadano y su partido. Los medios se expanden sin cesar dentro del conjunto social que abarcan todas las representaciones políticas y asumen funciones antes privativas de los partidos y de las corporaciones no gubernamentales (sindicatos, empresas y ejército). Como consecuencia de lo anterior, se produce una idea de una democracia participativa, en la cual más bien se delega la capacidad de decidir a otros operadores, a los medios y a sus actores, políticos o no.

Por otra parte, al poder normativo del Estado le es imperioso legitimarse ante el ciudadano en tiempos de crisis, por lo cual toma medidas preventivas para el acceso selectivo del público a la información. Surge entonces la siguiente pregunta: ¿qué posibilidades tiene el ciudadano para tener acceso a un rango amplio y diverso de recursos informativos y de comunicación? Golding y Murdock (1991) señalan que el abastecimiento de información se reduce si depende de las lógicas del mercado y el abastecimiento público y sin costo. Las posibilidades de acceso a información valiosa dependen, pues, de variables socioeconómicas, políticas y tecnológicas, fundamentalmente.

Luego entonces, la información mercadeable será accesible a individuos o corporaciones que tengan solvencia económica. De ahí 
la importancia de estudiar las tensiones entre los mercados y las promesas de ciudadanía completa, en términos de comunicación, para definir si somos consumidores o ciudadanos. Por ende, la ciudadanía se convierte en una actividad menos colectiva y política, y más en una actividad individual y económica.

\section{A manera de conclusión}

En este tema es aventurado pretender conclusiones definitivas, pues cada momento de la historia y su respectivo contexto plantean para los científicos sociales diferentes abordajes de la relación de interdependencia entre poder, Estado y medios de comunicación masiva.

La noción de poder abordada en este ensayo se emprende desde la perspectiva de que este fenómeno social puede y debe ser considerado como un constructo social, cuya conformación es mediada por la interacción de los sujetos que reelaboran, desde la cotidianidad de lo micro, las relaciones estructurales de índole social, económica y política.

Por tanto, la concepción de Estado propuesta por autores como Hegel (1987), Althusser (1982) y Gramsci (1998) se asume desde la posición de un ente regulador y legitimador de la normalización e institucionalizador de la vida social y política, y logra manifestarse mediante la promulgación de leyes y normas que le permiten establecer el estatuto jurídico que legitima la hegemonía de los grupos dominantes.

En este sentido, los procesos regulatorios que el Estado ha instituido actúan como mecanismos de control y vigilancia de la sociedad civil. Entre ellos, y en buena medida gracias a la mundialización de la esfera socioeconómica, uno de los instrumentos más refinados para llevar a cabo dichas tareas son los medios de comunicación masiva, merced a sus características constantemente renovadas de tipo simbólico y tecnológico que le permiten satisfacer los requerimientos de control y consenso artificial de la sociedad posmoderna. Por otra parte, habrá que reconocerle a los MCM poderes de tipo estructural-tecnológico, simbólico y normativo que le permiten 
y facilitan la construcción de los aconteceres como instrumentos de mediación de la normalización de lo cotidiano.

La pregunta que surge a partir de estas visiones del poder es: ¿la ciudadanía se percata de la importancia de su participación en la toma de decisiones colectivas en procesos políticos de crisis? Hay ejemplos de intervención en diferentes sentidos, cuando en momentos históricos la sociedad civil asume su responsabilidad social y produce los cambios necesarios para continuar, reorientar o impulsar la construcción de una sociedad más democrática y plural. Pero igual, y tal vez en mayor número, existen entornos en los cuales las élites del poder movilizan las fuerzas a su favor para continuar perpetuándose en el mismo. Y sobre todo en estos contextos, los MCM desempeñan un papel legitimador y normalizador del poder institucionalizado. Como propone Bisbal (2004), se trata de reflexionar si lo político hoy es atravesado por lo mass-mediático, pues está produciendo una nueva socialización de la esfera política y con ello una hibridación de la cultura política.

La construcción de la ciudadanía en la era de la mundialización plantea más preguntas que respuestas, sin embargo, si le otorgamos el valor social que tiene el espacio de la cotidianidad para construir un poder alterno, se entenderá la enorme responsabilidad que le toca a las generaciones futuras en cuanto a la participación ciudadana. En especial cuando organizaciones como los partidos políticos muestran signos de agotamiento o la institución del Estado es cada vez más débil ante el embate del poder económico de las grandes transnacionales. O cuando los MCM, en un proceso de sustitución de los partidos políticos, y aun peor, de sometimiento de éstos, proponen la transformación del quehacer y lenguaje político, convirtiéndolo en un producto que ahora se masifica y es objeto de consumo bajo la lógica del mercado.

De tal forma que la interdependencia estructural entre poder, Estado y medios de comunicación masiva no agota su análisis, pues desde la perspectiva de la Teoría Crítica permite el abordaje de los fenómenos sociopolíticos y comunicacionales que ocurren en escenarios concretos, en los cuales los sistemas sociales ven alterada su aparente normalización y hegemonía. 


\section{Referencias}

Acanda, Jorge Luis (2002), Sociedad civil y hegemonía, Centro de Investigaciones y Desarrollo de la Cultura Cubana "Juan Marinello", Cuba. (2003), "Amor y poder o relación imposible (Homenaje a Michel Foucault)", Revista Temas, núm. 35. Fondo para el Desarrollo de la Cultura y la Educación, Cuba, octubre-diciembre, pp. 108-119. Althusser, Louis (1982), Discutir el Estado, Folios, México.

Akzin, Benjamín (1964), Estado y nación, Fondo de Cultura Económica, México.

Bisbal, Marcelino (2004), "Otros lugares para pensar la política o las consecuencias en la política de la mediación comunicativa", Revista Metapolítica, núm. 40, marzo-abril, pp. 43-53.

Bobbio, Norberto y Michelangelo Bovero (1985), Origen y fundamentos del poder político, Grijalvo, México.

Bourdieu, Pierre (2000), Poder, derecho y clases sociales, Desclée de Brouwer, España.

Cordova, Arnoldo (1976), Sociedad y Estado en el mundo moderno, Grijalbo, México.

Chomsky, Noam y Edward S. Herman (1990), Los guardianes de la libertad. Propaganda, desinformación y consenso en los medios de comunicación de masas, Grijalbo-Mondadari, España.

Coutinho, Carlos Nelson (2000), "El concepto de sociedad civil en Gramsci y la lucha ideológica en el Brasil de hoy", en Dora Kanoussi (coord.), Gramsci en América, Plaza y Valdés, Benemérita Universidad de Puebla, Antonio Gramsci A.C., México.

Deutsch, Kart (1971), Los nervios del gobierno, Paidós, Argentina.

Flyvbjerg, Bent (2001), "Habermas o Foucault: ¿pensadores de la sociedad civil?", Estudios Sociológicos, vol. XIX, núm. 56, Colegio de México, mayo-agosto, pp. 295-324.

Foucault, Michel (1991), Microfísica del poder, La Piqueta, España. (1991), Microfisica del poder. Verdad y poder, La Piqueta, España. (1984), Un diálogo sobre el poder, Alianza, España.

Giddens, Anthony (1997), El poder en los escritos de Talcott Parsons en política, sociología y teoría social. Reflexiones sobre el pensamiento social clásico y contemporáneo, Paidós, España. 
Golding, Peter y Graham Murdock (1991), "Pobreza informativa y desigualdad política: la ciudadanía en la era de las comunicaciones privatizadas", Comunicación y Sociedad, núm. 9, Centro de Estudios de la Información y la Comunicación, Universidad de Guadalajara, México, pp. 53-62.

Gramsci, Antonio (1998), Cuadernos de la cárcel: Notas sobre Maquiavelo, sobre politica y sobre el Estado moderno, Juan Pablos, México.

Gurevitch, Michel y Jay G. Blumler (1981), "Relaciones entre los medios de comunicación de masas y la política: modelo para el análisis de sistemas de comunicaciones políticas", en James Curran, Sociedad y comunicación de masas, Fondo de Cultura Económica, México.

Hall, Stuart (1998), “Significado, representación, ideología: Althusser y los debates postestructuralistas", en Estudios culturales y comunicación, Paidós, España.

Hegel, Georg Wilhelm Friedrich (1987), Fundamentos de la filosofía del derecho, Siglo XXI, Argentina.

Heller, Herman (1985), Teoría del Estado, Fondo de Cultura Económica, México.

Landi, Oscar (1992), "Proposiciones sobre la videopolítica", en Héctor Schmucler y María Cristina Mata, Política y comunicación, Catálogos, Universidad Nacional de Córdoba, Argentina.

Lazzeri, Christian (1992), "Los signos del poder: ensayo sobre la política de Pascal", en Jean-Louis de Labarriere et al., Teoría política y comunicación, Gedisa, España.

Luhmann, Niklas (2000), Poder, Universidad Iberoamericana, Anthropos, México.

(2000), La realidad de los medios de masas, Universidad Iberoamericana, Anthropos, México.

Kaplan, Marcos (1978), Estado y sociedad, UNAM, México.

Kelsen, Hans (1968), Teoría pura del derecho, Editorial Universitaria de Buenos Aires, Argentina.

Krader, Lawrence (1972), La formación del Estado, Nueva Colección Labor, España.

Martín-Barbero, Jesús (1987), De los medios a las mediaciones, Gustavo Gili, México. 
Martín Serrano, Manuel (1989), La producción de comunicación social, CONEICC, México.

Orozco Gómez, Guillermo (1991), Recepción televisiva. Tres aproximaciones y una razón para su estudio, Universidad Iberoamericana (Cuadernos de comunicación y prácticas sociales), México. Sonntag, Heinz Rudolf y Héctor Valecillos (1977), El Estado en el capitalismo contemporáneo, Siglo XXI, México.

Thompson, John B. (1998), Los media y la modernidad. Una teoría de los medios de comunicación, Paidós Comunicación, España.

Weber, Max (1984), El político y el científico, Alianza, España. 